\title{
E-shape Multiband Patch Antenna for 4G, C-band and S-band Applications
}

\author{
Mehr-e-Munir' ${ }^{1}$, Khalid Mahmood ${ }^{2}$, Saad Hassan Kiani ${ }^{3}$ \\ Departmentof Electrical Engineering, Iqra National University, Peshawar Pakistan ${ }^{1,3}$ \\ Department of Electrical Engineering, University of Technology, Pakistan ${ }^{2}$
}

\begin{abstract}
In this study, a new E shape mounted on minowaki island patch antenna on FR4 substrate is presented for communication systems applications. With insertion of shortening pin between patch and ground plane, the proposed structure resonated on 6 frequencies; hence producing Hex-band response with good realized gain and directivity radiation values and patterns. Co axial cable is used as means of excitation to excite proposed structure with minimum impedance mismatch losses. The proposed design is miniaturized up to $60.66 \%$ and can be used for GSM, GPRS, 4G, WLAN and other S-band and Cband applications.
\end{abstract}

Keywords-Minowaki island patch; miniaturization; E shape; gain; directivity

\section{INTRODUCTION}

The development in wireless communication, microwave technology is increasing day by day with the passage of but these technologies requires smaller size of antennas which can be used in a numbers of applications, such as in 4G, S-band, C-band, mobile applications and other applications. As many telecommunication systems and radar communication system used several frequencies i.e. dual band antenna is more beneficial single band [1].

A new proposed antenna patch structure is suggested in this study for wireless communication application, the design results the multiband frequencies and reduced size antenna [2]. The size reduction is obtained by various ways such as using high permittivity substrate which gives good results of miniaturization but the cost of high permittivity substrate is expensive and unsuitable for low cost consumers' application [3]. Meta materials and magneto dielectrics are used for size reduction purpose but with these materials and dielectrics the miniaturization is archived but disadvantage is that this miniaturization gives the lower gain also the cost of these materials are expensive and complex to manufacture [4]. The Minowaki island shape or fractal patch results in miniaturization but this lower size of antenna gives lower gain [5].

Defected ground structure such as H, L, U shaped is used for size reduction of antenna which gives good gain and return loss but these structures gives very narrow bandwidth [6]. Defected patch structure such as H, U, Pi, E shaped is used for multiband operation of antenna which gives good return loss but these structure gives very lower gain [7]. Shorting pin method is also used for miniaturization purpose also as direction of current is changed with respect to location of the pin [8].

The use of Artificial Magnetic conductors (AMC), Split ring Resonators (SRR) has also been found effective in shifting the fundamental resonating frequency to lower levels but these techniques cause the gain to diminishing levels after few iterations. High cost and complex geometry also keeps researcher on edge at using Meta materials [9].

This paper presents a novel study of multiband enabled reduced sized antenna by introducing Defected ground structure in ground plane and $\mathrm{E}$ shape edged on resonating fractal patch. FR4 is used as a substrate having permittivity 4.2 which is easily available in the market, better efficiency, high bandwidth, low water absorption [10], [11]. Size reduction of patch antenna is obtained by mounting slots on ground plane while edging the patch with fractal and E slots has produce Hex Band response. All of the resonating frequencies have shown satisfactory performance parameters results with good radiation patterns and minimum mismatch losses. The proposed designed is carried out CST 2014 and can be used for $\mathrm{S}$ - and C-band applications.

\section{ANTENNA CONFIGURATION}

A. Width of Patch

Following formula is used for deriving patch width.

$$
W=\frac{C}{2 f_{o} \sqrt{\frac{(\in r+1)}{2}}}
$$

\section{B. Length of Patch}

Following formula is used for deriving patch length.

$$
L=L\left(e_{f f}\right)-2 \Delta L
$$

Where,

$$
L\left(e_{f f}\right)=\frac{C}{2 f_{o} \sqrt{\epsilon\left(r e_{f f}\right)}}
$$

And

$$
\in\left(r e_{f f}\right)=\frac{\epsilon r+1}{2}+\frac{\epsilon r-1}{4}\left(1+\frac{12 h}{W}\right)^{\frac{-1}{2}}
$$

A conventional antenna of $4.1 \mathrm{GHz}$ is designed after calculating width and patch of antenna. Regarding patch and ground structural dimensions with all slots information is covered in Table I. 
The resonating patch length and width is taken 16.95 and $22.47 \mathrm{~mm}$, respectively. Fractal slots are introduced having length and width 5.1 and $2.3 \mathrm{~mm}$. In center of Resonating patch, and E shape is mounted with $3 \mathrm{~mm}$ length and $1 \mathrm{~mm}$ of width. FR4 height is taken $2 \mathrm{~mm}$ and height of ground and patch is taken to be 0.8 and $0.245 \mathrm{~mm}$, respectively.

For miniaturization, ground plane is introduced with $\mathrm{H}$ and L Slots. The length and width of slots is taken as 7 and $9 \mathrm{~mm}$ and $\mathrm{L}$ slot length is taken as $5 \mathrm{~mm}$ and width $9 \mathrm{~mm}$.

Studies have shown that E shape slotting on various patch locations exhibit different response as the current is circulated around its corners [12]. The detailed geometry of proposed structure is shown in Fig. 1(a) and 1(b), respectively.

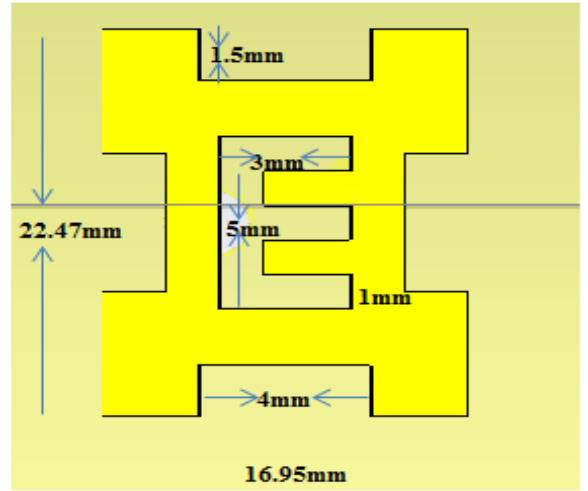

(a)

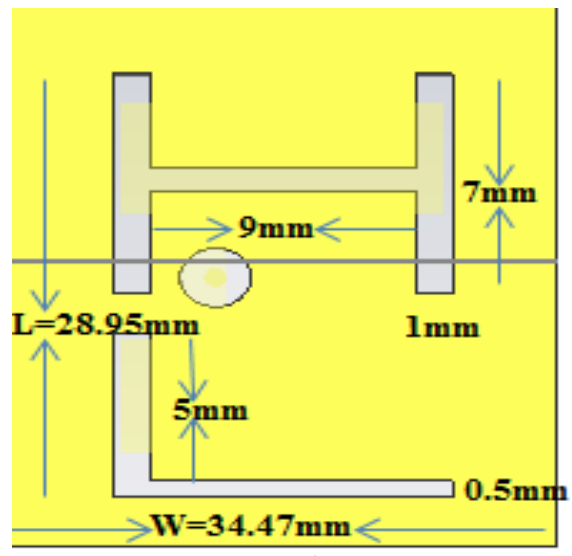

(b)

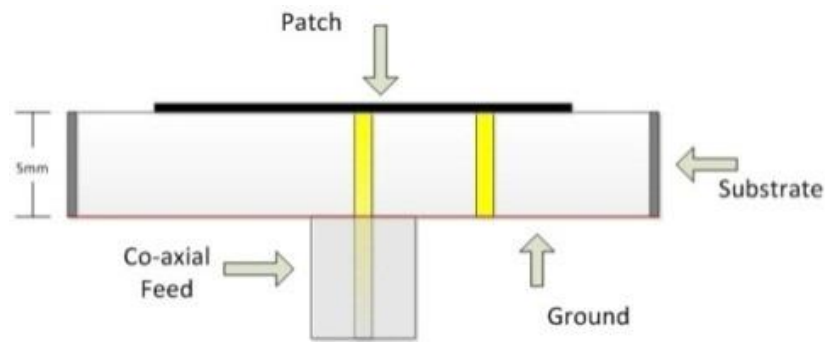

(c)

Fig. 1. (a) Front view, (b) ground view, (c) bottom view.

Fig. 1(c) shows the bottom view of our structure as evident from figure it is clear that coaxial probe feed is used as means of transmission for exciting patch antenna. The antenna is well impedance matched with Voltage Standing Wave Ration of 1.20 ensuring input power being delivered efficiently.

\section{RESULTS AND DISCUSSION}

In order to evaluate performance of our proposed design, different parameter results like realized gain, voltage standing wave ratio, directivity, reflection co efficient, efficiency, bandwidth were evaluated.

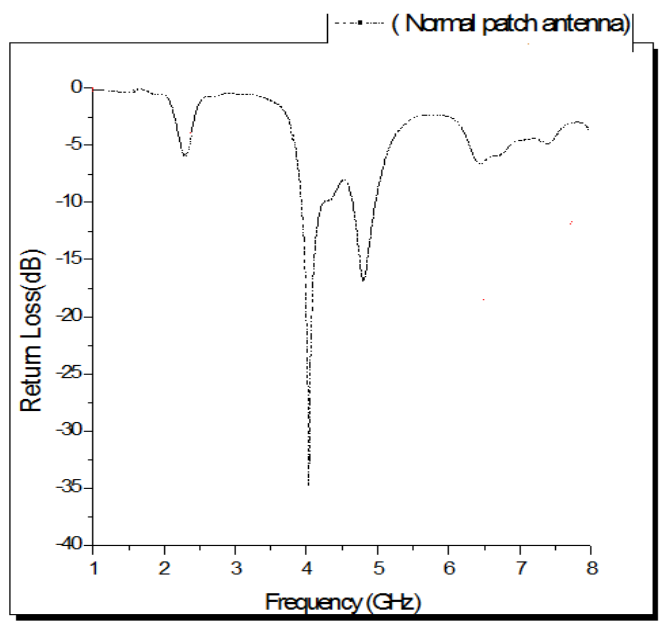

Fig. 2. Return loss of conventional antenna.

In Fig. 2, the antenna is designed for $4.1 \mathrm{GHz}$ and the miniaturized antenna is operating on $2.66 \mathrm{GHz}$ which shows in Fig. 3, due to the combination of different techniques i.e. defected patch structure, defected ground structure, shorting pin method, fractal patch structure. The frequencies are shifted downward due to the implementation of these techniques.

As our proposed design fundamental resonating frequency shifted downward to $2.66 \mathrm{GHz}$ while having the patch dimensions of 4.1 , our proposed design showed size reduction up to $60.67 \%$ since conventional design for $2.66 \mathrm{GHz}$ would require dimensions of $950 \mathrm{~mm}^{2}$ and our design has dimensions of $375.86 \mathrm{~mm}^{2}$ only.

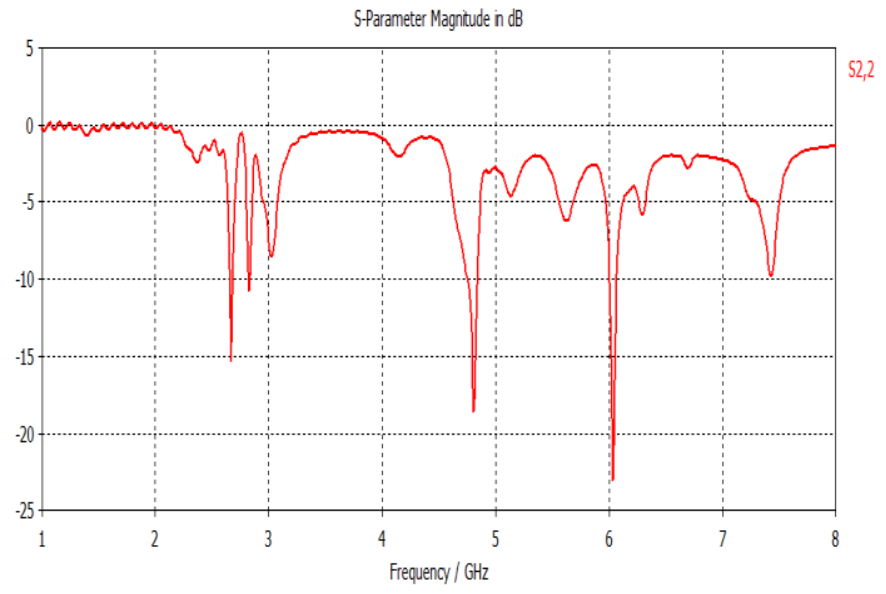

Fig. 3. Return loss of miniaturized antenna.

Reflection coefficient or Return loss graph is shown in Fig. 3. Return loss impedance bandwidth of $-10 \mathrm{~dB}$ clearly 
shows six different frequencies exhibiting Hex Band Response.

All of the resonating frequency performance parameters are covered in Table I and mismatch losses are shown in Table II.

TABLE I. SimUlation Results

\begin{tabular}{|l|l|l|l|l|}
\hline $\begin{array}{l}\text { FREQUENCY } \\
(\text { GHZ })\end{array}$ & DIRECTIVITY & GAIN & BANDWIDTH & RETURN LOSS \\
\hline 2.66 & 4.25 & 3.43 & 70 & -15.2 \\
\hline 2.87 & 3.68 & 3.75 & 40 & -20.7 \\
\hline 3.01 & 4.15 & 3.69 & 30 & -8.5 \\
\hline 4.80 & 5.41 & 4.71 & 110 & -18.7 \\
\hline 6.03 & 5.41 & 4.71 & 190 & -23.7 \\
\hline 7.42 & 5.46 & 4.28 & 81 & -10.1 \\
\hline
\end{tabular}

TABLE II. MISSMATCH LOSSES

\begin{tabular}{|l|l|l|l|l|l|l|}
\hline $\begin{array}{l}\text { FREQUEMCY } \\
\text { (GHz) }\end{array}$ & 2.66 & 2.87 & 3.01 & 4.80 & 6.03 & 7.42 \\
\hline VSWR & 1.02 & 1.25 & 1.11 & 1.09 & 1.05 & 1.21 \\
\hline
\end{tabular}

Fig. 4 mentions and shows all the radiation frequencies 1D radiation patterns. From Radiating Frequencies, it is clear that our proposed structure is resonating at six different directions which is a good response for an antenna since this behavior leads to usage of structure for different application purposes.

As in $2.66 \mathrm{GHz}$ the main lobe magnitude is $3.4 \mathrm{~dB}$, main

Lobe direction is $80.0 \mathrm{deg}$ and angular width is $86.2 \mathrm{deg}$ while side lobe level is $-6.8 \mathrm{~dB}$.

In $2.87 \mathrm{GHz}$ the main lobe magnitude is $3.7 \mathrm{~dB}$, main lobe direction is $83.0 \mathrm{deg}$ and angular width is $86.3 \mathrm{deg}$ while side lobe level is $-14.2 \mathrm{~dB}$.

In $3.01 \mathrm{GHz}$ the main lobe magnitude is $3.7 \mathrm{~dB}$, main lobe direction is $88.0 \mathrm{deg}$ and angular width is $93.1 \mathrm{deg}$.

In $6.03 \mathrm{GHz}$ the main lobe magnitude is $2.7 \mathrm{~dB}$, main lobe direction is $00.0 \mathrm{deg}$ and angular width is $103.4 \mathrm{deg}$ while side lobe level is $-4.7 \mathrm{~dB}$

In $4.80 \mathrm{GHz}$ the main lobe magnitude is $4.7 \mathrm{~dB}$, main lobe direction is $100.0 \mathrm{deg}$ and angular width is $190.7 .3 \mathrm{deg}$.

In $7.42 \mathrm{GHz}$ the main lobe magnitude is $2.8 \mathrm{~dB}$, main lobe direction is $180.0 \mathrm{deg}$ and angular width is $42.7 \mathrm{deg}$ while side lobe level is $-11.6 \mathrm{~dB}$.
Farfield Gain Abs (Phi=90)

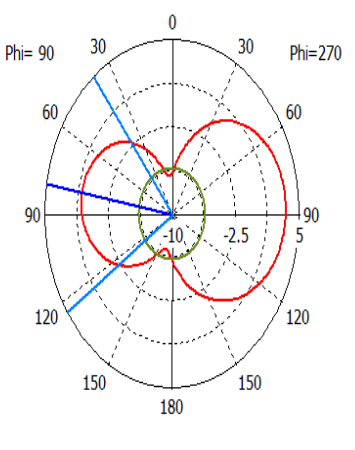

Theta / Degree vs. dB

(a)

Farfield Gain Abs (Phi=90)

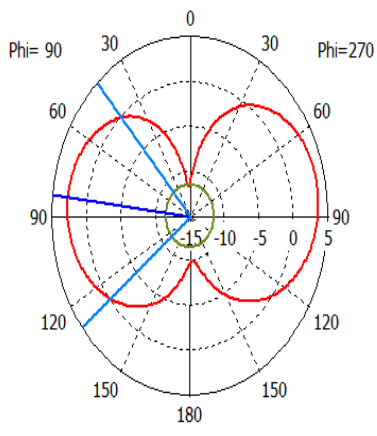

Theta / Degree vs. dB (b)

Farfield Gain Abs (Phi=90)

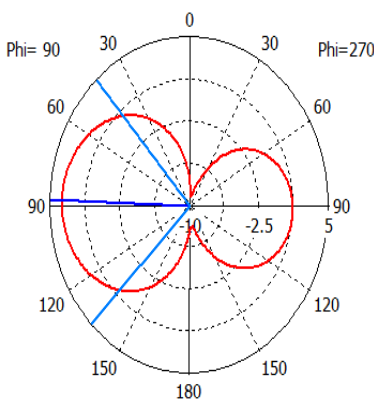

Theta / Degree vs. dB

(c)

Farfield Gain Abs (Phi $=90$ )

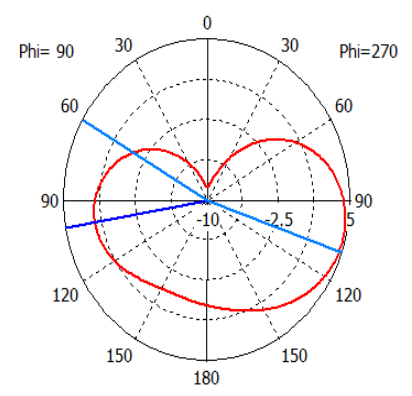

Theta / Degree vs. dB
Frequency $=2.66$

Main lobe magnitude $=3.4 \mathrm{~dB}$ Main lobe direction $=80.0$ deg. Angular width $(3 \mathrm{~dB})=86.2 \mathrm{deg}$. Side lobe level $=-6.8 \mathrm{~dB}$ quency $=2.87$

Main lobe magnitude $=3.7 \mathrm{~dB}$ Main lobe direction $=83.0 \mathrm{deg}$. Angular width $(3 \mathrm{~dB})=86.3 \mathrm{deg}$ Side lobe level $=-14.2 \mathrm{~dB}$

farfield $(f=3.01)$ [2]
Frequency $=3.01$

Main lobe magnitude $=3.7 \mathrm{~dB}$ Main lobe direction $=88.0 \mathrm{deg}$. Angular width $(3 \mathrm{~dB})=93.1 \mathrm{deg}$.

farfield $(f=4.80)[2]$
Frequency $=4.8$ Main lobe magnitude $=4.7 \mathrm{~dB}$ Main lobe direction $=100.0 \mathrm{deg}$. Angular width $(3 \mathrm{~dB})=190.7 \mathrm{deg}$. 


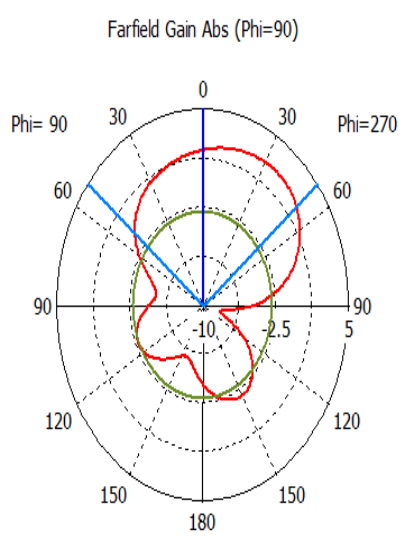

Theta / Degree vs. dB

(e)

Farfield Gain Abs (Phi=90)

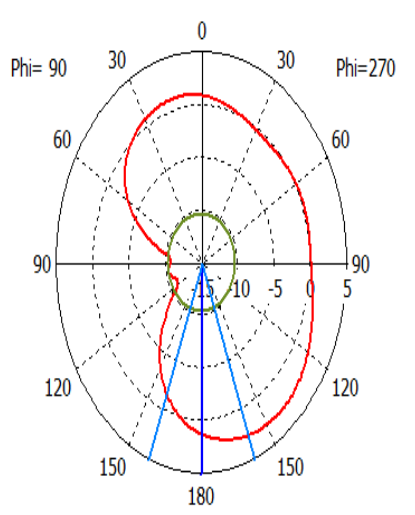

Theta / Degree vs. dB
Frequency $=6.03$

Main lobe magnitude $=2.7 \mathrm{~dB}$

Main lobe direction $=0.0 \mathrm{deg}$.

Angular width $(3 \mathrm{~dB})=103.4 \mathrm{deg}$.

Side lobe level $=-4.7 \mathrm{~dB}$

Frequency $=7.42$

Main lobe magnitude $=2.8 \mathrm{~dB}$

Main lobe direction $=180.0 \mathrm{deg}$. Angular width $(3 \mathrm{~dB})=42.7 \mathrm{deg}$. Side lobe level $=-11.6 \mathrm{~dB}$

(f)

Fig. 4. 1D Ration Pattern of the proposed miniaturized antenna for (a) at $\mathrm{f}=2.66 \mathrm{GHz}$ (b) at $\mathrm{f}=2.87 \mathrm{GHz}(\mathrm{c})$ at $\mathrm{f}=3.01 \mathrm{GHz}(\mathrm{d})$ at $\mathrm{f}=4.80 \mathrm{GHz}$ (e) at $\mathrm{f}=6.03 \mathrm{GHz}$ and $(\mathrm{f})$ at $\mathrm{f}=7.42 \mathrm{GHz}$.

Fig. 5 shows 3D radiation pattern of miniaturized proposed antenna. All the images are extracted from Computer Simulation technology 2014.

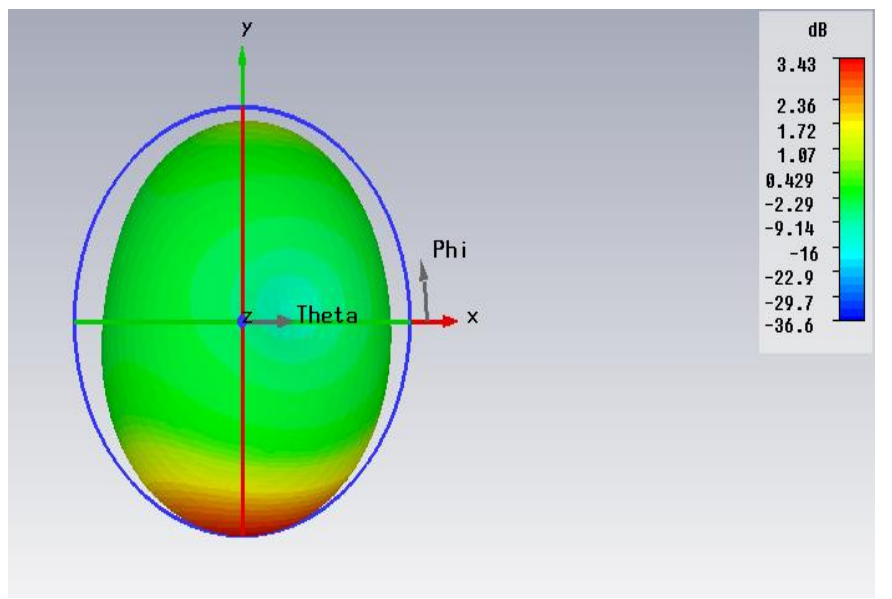

(a)

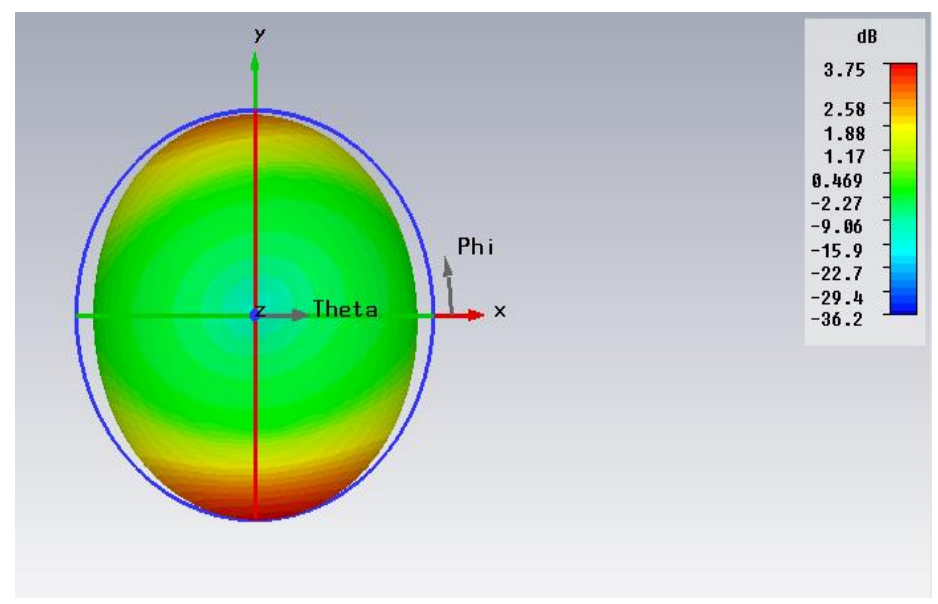

(b)

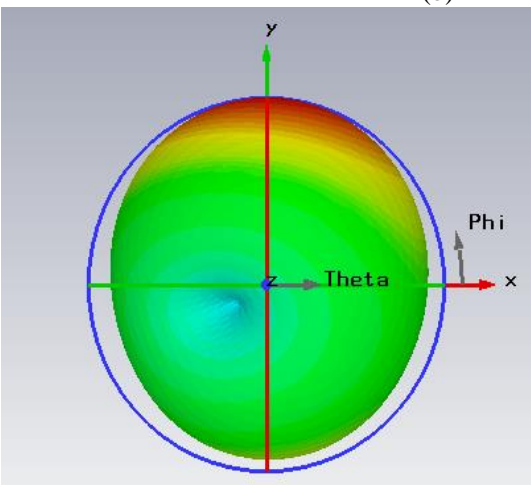

dB

3.69

2.54 1.85
1.15
0.462

0.462
-2.27

$-2.27$

$-15.9$

$-22.7$

-29.5
-36.3

(c)

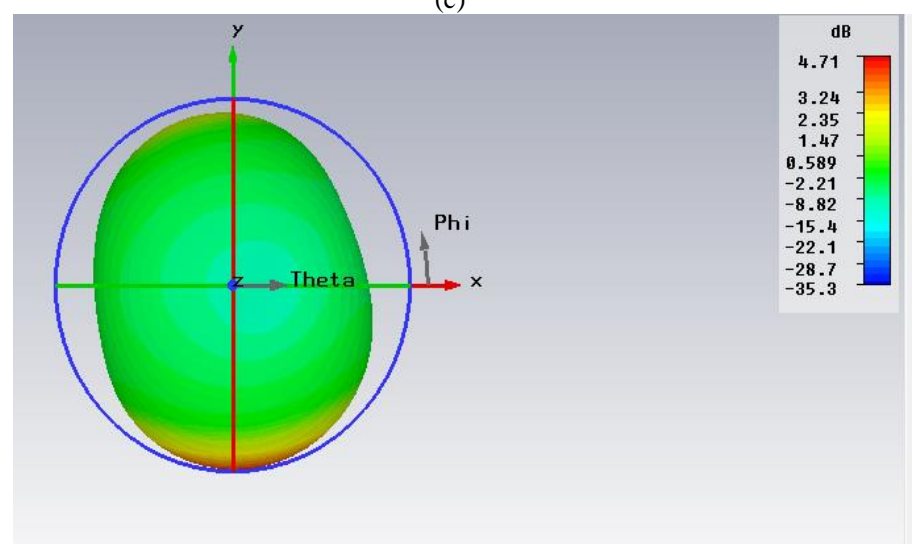

(d)

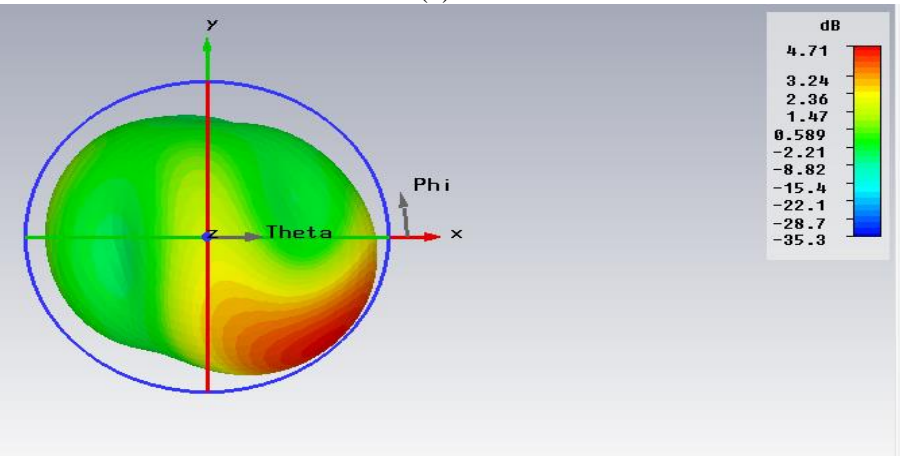

(e) 


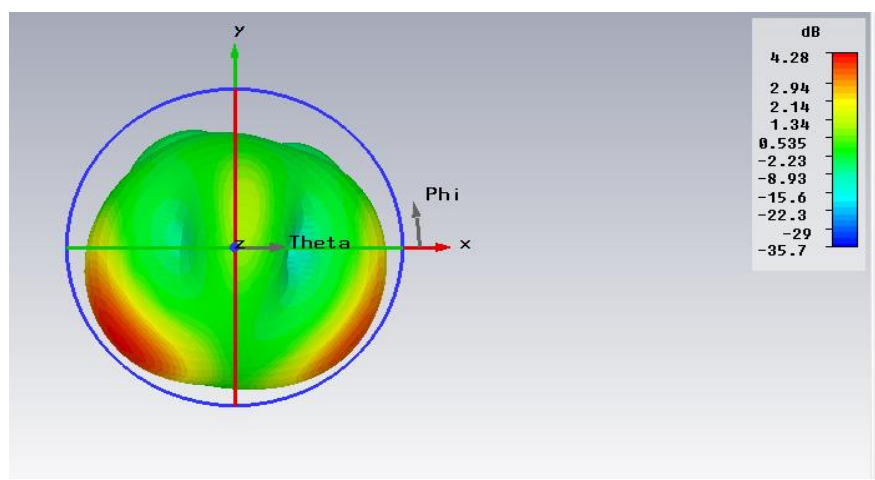

(f)

Fig. 5. (a) 3D Gain of $2.66 \mathrm{GHz}$, (b) 3D Gain of $2.87 \mathrm{GHz}$, (c) 3D Gain of $3.01 \mathrm{GHz}$, (d) 3D Gain of 4.80GHz, (e) 3D Gain of $6.03 \mathrm{GHz}$, (f) 3D Gain of $7.42 \mathrm{GHz}$,

\section{CONCLUSION}

In this paper, a novel fractal $\mathrm{E}$ slot mounted patch is proposed with $\mathrm{H}$ and $\mathrm{L}$ slots in ground. With Slots in ground miniaturization response is observed and due to fractal slotting, the antenna exhibit Hex Band Response with reduction up to $60 \%$. Antenna performance parameters showed excellent results as gain varied form $3.79 \mathrm{~dB}$ to $4.7 \mathrm{~dB}$ with bandwidth up to $180 \mathrm{MHz}$ and minimum mismatch losses. The proposed antenna can be used for different $\mathrm{S}$ and $\mathrm{C}$ band application Systems.

\section{REFERENCES}

[1] S. Hassan, K. Mahmood and M. Munir, "U Patch Antenna using Variable Substrates for Wireless Communication Systems", International Journal of Advanced Computer Science and Applications, vol. 7, no. 12, 2016

[2] M. MUNIR, S. S. QURESHI, S. H. KIANI, K. MAHMOOD, J. KHAN, "Performance Analysis between Single and Dual Substrate Patches for
Wireless Communication and Applications", Sindh University Research Journal,vol.49, no.1, 2017

[3] Kiani, S. H., Mahmood, K., Shafeeq, S., Munir, M., \& Khan, K. M. (2016). A Novel Design of Miniaturaized Patch Antenna Using Different Substrates for S-Band and C-Band Applications. International Journal of Advanced Computer Science and Applications (IJACSA), $7(7)$.

[4] Hwang, S., Lee, B., Kim, D. H., \& Park, J. Y. (2018). Design of S-Band Phased Array Antenna with High Isolation Using Broadside Coupled Split Ring Resonator. Journal of Electromagnetic Engineering And Science, 18(2), 108-116.

[5] S. Hassan, K. Mahmood, M. Munir and A. James, "A Novel Design of Patch Antenna using U-Slot and Defected Ground Structure", International Journal of Advanced Computer Science and Applications, vol. 8, no. 3, 2017.

[6] Mehre-e Munir; Ahsan Altaf; Muhammad Hasnain," Miniaturization of microstrip fractal H-Shape patch antenna using stack configuration for wireless applications", in IEEE 2nd International Conference on Recent Trends in Information Systems (ReTIS),Kolkata, 2015

[7] Mehre-e-Munir; Ahsan Altaf; Syed Imran Hussain Shah, "Miniaturization of multiband patch antenna using stack configuration", in 17th IEEE International Multi Topic Conference, Karachi, 2014

[8] Mehr-e-Munir; Khalid Mahmood," Miniaturized microstrip patch antenna using stack configuration for S-band, C-band \& mobile applications", in International Conference on Emerging Technologies (ICET),Peshawar,2015

[9] Mehr-e-Munir; Umar Farooq "Multiband microstrip patch antenna using DGS for L-Band, S-Band, C-Band \& mobile applications", in 13th International Conference on Modern Problems of Radio Engineering, Telecommunications and Computer Science (TCSET),Ukraine,2016

[10] Li, Yujian, and Kwai-Man Luk. "60-GHz substrate integrated waveguide fed cavity-backed aperture-coupled microstrip patch antenna arrays." IEEE Transactions on Antennas and Propagation 63, no. 3 (2015): 1075-1085.

[11] D. Sievenpiper, H. P. Hsu, J. Schaffner, G. Tangonan, R. Garcia, and S. Ontiveros, "Low profile, four sector diversity antenna on high impedance ground plane," Electron. Lett. vol. 36, pp. 1343 1345, 2000.

[12] Zhang, X. Yang, "Study of a slit cut on a microstrip antenna and its applications," Microwave and Optical Technology Letters, vol.18, no.4, pp.297- 300, 1998. 